\title{
Detecção de tendências hidroclimáticas interanual na bacia do rio São Francisco
}

\section{Detection of interannual hydro-climate trends in the São Francisco river basin}

Data de entrada: 16/07/2016

Data de aprovação: $16 / 12 / 2016$

\section{Resumo}

No presente trabalho realizaram-se análises estatísticas da variabilidade anual das temperaturas mínima, média e máxima, das precipitações pluviométricas e dos índices de vazão ao longo da bacia do rio São Francisco. Procurou-se identificar, por meio de testes estatísticos, pontos de mudança no comportamento hidrológico e climático em séries temporais. Utilizaram-se a Análise de Regressão Linear e os testes não paramétricos de Mann-Kendall e de Pettitt. Trabalhou-se com as medições realizadas pela Agência Nacional de Águas, em 24 localidades, e pelo Instituto Nacional de Meteorologia, em 15 localidades. Os resultados, apresentados em forma de gráficos, tabelas e mapas, confirmam que a maioria das localidades avaliadas não registrou tendências climáticas, em particular na precipitação. As análises dos dados de vazão não revelam tendências nas localidades do montante da Barragem de Sobradinho. Contudo, foram observadas tendências em todas as localizações da jusante dessa barragem a partir de 1986. Essa data é próxima do início de operação dessa barragem, o que pode ser o indício de uma das causas para a mudança ambiental verificada naquela região do Brasil. Palavras-chave: Análises de tendências. Mudanças ambientais. Bacia hidrográfica.

\section{Abstract}

In the present work, a statistical analysis was performed, considering the annual variability of minimum, average and maximum temperatures, rainfall and flow rates in Sao Francisco river basin. Using statistical tests, we aimed to identify changing points in both the hydrologic and climatic behaviours of the time series. Linear Regression Analysis and Mann-Kendall and Pettitt nonparametric tests were applied. The observations were made by the National Water Agency, in 24 localities, and the National Institute of Meteorology, in 15 localities. The results, presented in the form of graphs, tables and maps, confirmed that most of the evaluated localities did not record climate trends, particularly in precipitation. The analysis of flow data did not show trends in localities upstream Sobradinho Dam. However, trends for all locations downstream Sobradinho Dam after 1986 were observed. This date is close to the start of the dam operation, what may represent one of the causes for the environmental changes verified in that Brazilian region. Keywords: Trends analysis. Environmental changes. Watershed.

\footnotetext{
Júlio César Penereiro - Professor e pesquisador do Programa de Pós-Graduação Stricto Sensu em Sistemas de Infraestrutura Urbana da Pontifícia Universidade Católica de Campinas (PUC-Campinas). E-mail: jcpapuc-campinas.edu.br.

Vanessa Fernanda Vick Garcia - Engenheira Ambiental pela Pontifícia Universidade Católica de Campinas (PUC-Campinas)

"Endereço para correspondência: Centro de Ciências Exatas, Ambientais e de Tecnologias (CEATEC) - PUC-Campinas, Rodovia Dom Pedro I, km 136, Parque das Universidades, 13086-900, Campinas, SP. Telefone: (19) 3343-7023.
} 


\section{INTRODUÇÃO}

Desde a década de 1980, por meio de métodos científicos, os estudos que indicam as possibilidades de variação no clima em nível regional e global vêm despertando interesses na comunidade acadêmica, científica e no público em geral. No que concerne aos aspectos científicos, o Painel Intergovernamental de Mudanças Climáticas (IPCC, na sigla em inglês) do Programa das Nações Unidas para o Meio Ambiente (PNUMA) é o órgão mundial que está encarregado de apoiar e divulgar, por meio de relatos e trabalhos científicos, as avaliações do clima e os cenários de mudanças climáticas para o futuro.

Apesar da existência de muitas controvérsias a respeito da influência humana sobre o clima terrestre, o Quarto e Quinto Relatórios Científicos do IPCC, nas siglas IPCC-AR4 (MEEHL et al., 2007) e IPCC-AR5 (TOLEDO, 2013; IPCC, 2016), respectivamente, apresentam evidências de variações dos parâmetros climáticos desde meados da década de 1970, sendo possível afirmar inequivocamente que uma parte da variabilidade do clima seja uma consequência do atual aquecimento global observado. As principais conclusões extraídas desses dois relatórios sugerem com grau superior a $90 \%$ de confiabilidade, que o aquecimento global das últimas cinco décadas é causado pelas atividades antropogênicas. Nesse sentido, as evidências de mudanças nos regimes das temperaturas e precipitações são frequentemente apontadas como consequência da interferência dos seres humanos no ambiente, especialmente devido a desmatamentos, queimadas, emissões de gases de efeito estufa e partículas de aerossóis, além da crescente urbanização sem planejamento e o uso do solo de forma inadequada (MARENGO, 2007). Não obstante essas interferências, sabe-se que o ciclo hidrológico de um rio, ou de uma bacia hidrográfica, é um processo complexo que também é influenciado em suas características físicas pelo clima local, assim como pelas atividades humanas no seu entorno (ZHENMEl et al., 2008).

Considerando o acelerado desenvolvimento urbano e agroindustrial ocorrido nas últimas décadas no Brasil, em particular em várias partes das regiões Norte e Nordeste, esse fenômeno socioeconômico tem provocado a degradação dos recursos hídricos dessas regiões, tanto nos aspectos quantitativos como qualitativos. Essa degradação vem ocorrendo, principalmente, devido ao uso da água e do solo sem um gerenciamento adequado e à quase ausência de tratamento do esgoto urbano e industrial (GROPPO et al., 2005). Além desses fatores, as queimadas, em conjunto com a poluição e, consequentemente, a destruição da mata ciliar, em médio e longo prazo, podem degradar e diminuir a capacidade de armazenamento de água da sub-bacia que lhe pertence, alterando o regime de vazão dos rios ali existentes (ANA, 2013). Constata-se, portanto, que as matas ciliares participam de processos vitais para a manutenção dos recursos hídricos, sendo por isso importante a proteção e preservação dos remanescentes de vegetação no que tange uma largura mínima de $30 \mathrm{~m}$ das margens de um determinado rio, além do escoamento da água em decorrência das chuvas precipitadas em bacias hidrográficas.

Os estudos sobre alterações nos padrões climáticos locais e regionais em bacias hidrográficas são também de fundamental importância para verificar o comportamento desses sistemas ao longo dos anos. Essa conduta possibilita uma melhor compreensão desses sistemas ambientais para realizar previsões visando ao planejamento dos recursos de água por meio de reservatórios para o abastecimento de cidades, irrigação para agricultura, geração de energia elétrica, dentre outros (ANA, 2013).

Uma maneira de estudar o clima local e regional engloba análises nas variabilidades dos parâmetros climatológicos, particularmente aquelas medidas relacionadas às séries temporais de temperaturas, precipitações, umidade relativa do ar e pressão atmosférica. Do ponto de vista matemático, para realizar estudos confiáveis envolvendo as variáveis climáticas é necessário aplicar e analisar métodos estatísticos paramétricos e não paramétricos, que possam fornecer informações relevantes para a 
análise de variabilidades, investigação de tendências climáticas e, eventualmente, de outras variáveis relacionadas, como é o caso de vazões em rios (ALEXANDRE et al., 2010). Nesse sentido, métodos não paramétricos, como os de Mann-Kendall e de Pettitt, são frequentemente empregados, pois, segundo Sansigolo e Nery (2000), eles possuem um maior embasamento estatístico para modelos teóricos de descrição climática, apesar das dificuldades no estabelecimento da existência de tendências significativas devido à grande variabilidade natural das medidas meteorológicas.

A detecção de tendência tem sido amplamente utilizada por meio de métodos estatísticos (BACK, 2001; GROPPO et al., 2005; MORAES et al. 1995; ALEXANDRE et al., 2010; PENEREIRO et al., 2016; entre outros). Contudo, não há na literatura estudos utilizando métodos não paramétricos em séries temporais climáticas e hidrológicas observadas em locais na região da bacia hidrográfica do rio São Francisco. É nessa vertente que o presente artigo foi direcionado.

\section{OBJETIVOS}

Foram investigados, por meio de análises exploratórias de séries temporais, índices anuais das temperaturas (mínima, média e máxima), precipitação pluviométrica e vazão nas regiões pertencentes à bacia hidrográfica do rio São Francisco, uma das mais importantes das regiões Sudeste e Nordeste do Brasil, devido aos seus aspectos socioeconômico e ambiental. $O$ estudo visou analisar a variabilidade anual ao longo de cada série temporal de parâmetros hidrológicos e climáticos observados em localidades da referida bacia. Por meio desse procedimento, foi possível identificar pontos de mudança brusca no comportamento de uma determinada série durante o período em que foi observada e, por meio de análises estatísticas, determinar a ocorrência de tendências. Para tanto, empregaram-se métodos estatísticos paramétricos e não paramétricos. Os resultados das aplicações desses testes, em particular os de Mann-Kendall e de Pettitt, possibilitaram confeccionar mapas relativos às distribuições de tendências para cada variável hidroclimática em questão e, a partir desses procedimentos, avaliar as possíveis influências de ações antropogênicas e naturais ao longo referida bacia.

\section{METODOLOGIA}

\section{1 Área de estudo e descrição} dos dados utilizados

O curso principal do rio São Francisco, mostrado na Figura 1, tem 2.814 km de extensão no sentido sul-norte, com nascente no município de São Roque de Minas (MG) e a foz no Oceano Atlântico, entre os estados de Alagoas e Sergipe, onde se observa uma vazão média anual de $2.980 \mathrm{~m}^{3} \mathrm{~s}^{-1}$. Essa bacia está dividida em quatro unidades hidrográficas: Alto São Francisco (ASF), que se estende desde sua nascente na Serra da Canastra, em São Roque de Minas (MG), até a cidade de Pirapora (MG), Médio São Francisco (MSF), que vai de Pirapora (MG) até Remanso (BA), Submédio São Francisco (SMSF), que se estende de Remanso (BA) até Paulo Afonso (BA) e Baixo São Francisco (BSF), que vai de Paulo Afonso (BA) até sua foz no Oceano Atlântico. Além do São Francisco, os principais rios da região são: das Velhas (689 km), Grande (502 km), Verde Grande (458 km), Paracatu (448 km), Urucuia (381 km), Paramirim (345 km), Pajeú (333 km), Preto (315 km) e Jacaré (297km). A bacia hidrográfica possui uma área total de drenagem estimada em $619.544 \mathrm{~km}^{2}$, o que corresponde a $8 \%$ do território nacional, influenciando os habitantes de 409 cidades que se inserem dentro do denominado vale do São Francisco (Codevasf, 2015).

O clima dessa bacia é caracterizado como semiárido, abrangendo $57 \%$ do referido território hidrográfico, possuindo uma temperatura média entre $23^{\circ} \mathrm{C}$ e $27^{\circ} \mathrm{C}$. Trata-se de uma região vulnerável e sujeita a períodos críticos de prolongadas estiagens, que apresenta várias zonas geográficas e diferentes índices de aridez, resultado de baixa pluviosidade e alta evapotranspiração, fazendo com que o rio São Francisco desempenhe um importante papel na região Nordeste do Brasil (MMA, 2006). 


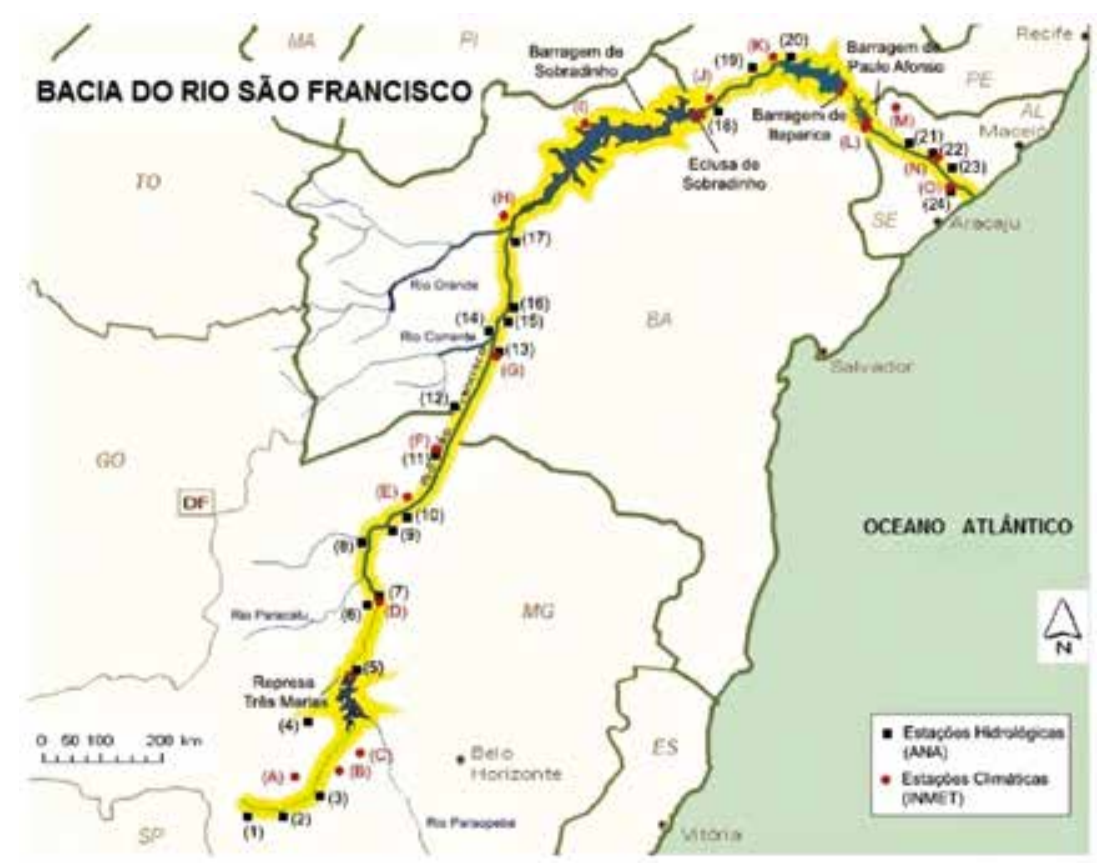

Figura 1 - Percurso do rio São Francisco e de seus principais afluentes,

destacando os locais das estações do INMET e da ANA. Segundo dados do Instituto Brasileiro de Geografia e Estatística (IBGE), a população total na região hidrográfica do São Francisco, no ano de 2010, era de 14,3 milhões de habitantes, sendo que a população urbana representava $77,0 \%$. A densidade populacional média na bacia é de 22,4 hab/ $\mathrm{km} 2$, igual à média brasileira (IBGE, 2016).

A bacia do São Francisco tem uma potência hidroelétrica instalada de aproximadamente 11.000 MW, distribuídos principalmente nas usinas de Três Marias, Queimado, Sobradinho, Itaparica, Complexo Paulo Afonso e Xingó. Juntas, essas usinas representam a principal fonte de energia para o Nordeste brasileiro. Não obstante, as usinas de Três Marias, Sobradinho e Itaparica se destacam por terem um papel fundamental na regularização das vazões do rio São Francisco (Codevasf, 2015).

Neste trabalho foram usadas as médias diárias contidas nas séries temporais observadas em localida- des distribuídas ao longo do rio São Francisco. Para tanto, utilizaram-se as observações diárias das variáveis relacionadas à precipitação pluviométrica anual (Prec.), temperatura mínima anual (T-mín.), temperatura média anual ( $T$-méd.) e temperatura máxima anual (T-máx.) de 15 cidades cujos dados estão disponibilizados no Instituto Nacional de Meteorologia (INMET, 2016), além da vazão média anual (Vaz.) observada em 24 localidades disponibilizadas no endereço eletrônico da Agência Nacional de Águas (ANA, 2015). Na Figura 1 destacam-se as posições aproximadas das estações meteorológicas e hidrológicas cujos dados observados foram utilizados neste trabalho (estação do INMET, em letra e círculo vermelho; estação da ANA, em número e quadrado preto). As informações básicas dessas estações, tais como as coordenadas geográficas, altura em relação ao nível do mar e o período de cada série temporal trabalhada, estão apresentadas na Tabela 1, para estações da ANA, e na Tabela 2, para estações do INMET. 
Tabela 1 - Relação dos locais com as estações medidoras da ANA.

\begin{tabular}{|c|c|c|c|c|c|}
\hline$\#$ & Local & Estação & Lat. (') & Long. (') & Período (anos) \\
\hline 1 & Vargem Bonita (MG) & 40025000 & $-20,33$ & $-46,37$ & $1954-2015$ \\
\hline 2 & Iguatama (MG) & 40050000 & $-20,17$ & $-45,72$ & $1935-2015$ \\
\hline 3 & Moema (MG) & 40070000 & $-19,78$ & $-45,48$ & $1967-2015$ \\
\hline 4 & Abaeté (MG) & 40100000 & $-19,28$ & $-45,29$ & $1958-2015$ \\
\hline 5 & Três Marias (MG) & 41020002 & $-18,19$ & $-45,25$ & $1957-2015$ \\
\hline 6 & Buritizeiro (MG) & 42210000 & $-16,66$ & $-45,08$ & $1959-2015$ \\
\hline 7 & Pirapora (MG) & 41135000 & $-17,37$ & $-44,94$ & $1968-2015$ \\
\hline 8 & São Romão (MG) & 43200000 & $-16,37$ & $-45,07$ & $1953-2015$ \\
\hline 9 & São Francisco (MG) & 42000000 & $-15,95$ & $-44,87$ & $1935-2015$ \\
\hline 10 & Pedras Maria da Cruz (MG) & 44290002 & $-15,61$ & $-44,40$ & $1973-2015$ \\
\hline 11 & Manga (MG) & 44500000 & $-14,76$ & $-43,93$ & $1937-2015$ \\
\hline 12 & Carinhanha (BA) & 45298000 & $-14,30$ & $-43,76$ & $1932-2015$ \\
\hline 13 & Bom Jesus Lapa (BA) & 45480000 & $-13,26$ & $-43,44$ & $1941-2015$ \\
\hline 14 & Sítio do Mato (BA) & 46035000 & $-12,87$ & $-43,38$ & $1969-2015$ \\
\hline 15 & Paratinga (BA) & 46105000 & $-12,70$ & $-43,23$ & $1977-2015$ \\
\hline 16 & Ibotirama (BA) & 46150000 & $-12,18$ & $-43,22$ & $1954-2015$ \\
\hline 17 & Morpará (BA) & 46360000 & $-11,56$ & $-43,28$ & $1954-2015$ \\
\hline 18 & Juazeiro (BA) & 48020000 & $-9,41$ & $-40,50$ & $1932-2015$ \\
\hline 19 & Sta. Maria da Boa Vista (PE) & 48290000 & $-8,81$ & $-39,82$ & $1977-2015$ \\
\hline 20 & Belém S. Francisco (PE) & 48590000 & $-8,63$ & $-39,24$ & $1977-2015$ \\
\hline 21 & Piranhas (AL) & 49330000 & $-9,63$ & $-37,76$ & $1979-2015$ \\
\hline 22 & Pão de Açúcar (AL) & 49370000 & $-9,75$ & $-37,45$ & $1959-2015$ \\
\hline 23 & Traipu (AL) & 49660000 & $-9,97$ & $-37,00$ & $1977-2015$ \\
\hline 24 & Propriá (SE) & 49705000 & $-10,21$ & $-36,82$ & $1977-2015$ \\
\hline & & & & & \\
\hline
\end{tabular}

Tabela 2 - Relação dos locais com as estações medidoras do INMET.

\begin{tabular}{|c|c|c|c|c|c|c|}
\hline$\#$ & Cidade & Estação & Lat. $\mathbf{(}^{\circ}$ ) & Long. $\mathbf{(}^{\circ}$ ) & Alt. (m) & Período (anos) \\
\hline A & Bambuí (MG) & 83582 & $-20,03$ & $-46,00$ & 661,27 & $1986-2015$ \\
\hline B & Bom Despacho (MG) & 83533 & $-19,71$ & $-45,36$ & 695,00 & $1981-2015$ \\
\hline C & Pompéu (MG) & 83570 & $-19,21$ & $-45,00$ & 690,91 & $1972-2015$ \\
\hline D & Pirapora (MG) & 83483 & $-17,35$ & $-44,91$ & 505,24 & $1961-2015$ \\
\hline E & Januária (MG) & 83386 & $-15,45$ & $-44,36$ & 473,71 & $1976-2015$ \\
\hline F & Carinhanha (BA) & 83408 & $-14,28$ & $-43,76$ & 450,18 & $1990-2015$ \\
\hline G & Bom Jesus da Lapa (BA) & 83288 & $-13,26$ & $-43,41$ & 439,90 & $1986-2015$ \\
\hline H & Barra (BA) & 83179 & $-11,08$ & $-43,16$ & 401,58 & $1986-2015$ \\
\hline I & Remanso (BA) & 82979 & $-9,63$ & $-42,10$ & 400,51 & $1986-2015$ \\
\hline J & Petrolina (PE) & 82983 & $-9,36$ & $-40,46$ & 370,46 & $1991-2015$ \\
\hline K & Cabrobó (PE) & 82886 & $-8,51$ & $-39,33$ & 341,46 & $1992-2015$ \\
\hline L & Paulo Afonso (BA) & 82986 & $-9,36$ & $-38,21$ & 252,69 & $1986-2015$ \\
\hline M & Água Branca (AL) & 82989 & $-9,28$ & $-37,90$ & 605,34 & $1986-2015$ \\
\hline N & Pão de Açúcar (AL) & 82990 & $-9,75$ & $-37,43$ & 19,10 & $1995-2015$ \\
\hline O & Propriá (SE) & 83097 & $-10,19$ & $-36,86$ & 19,92 & $1992-2015$ \\
\hline
\end{tabular}


Caso houvesse falhas nas observações diárias de uma determinada série temporal, optou-se pela utilização do cálculo da média com grau três, isto é, calculando a média dos três dias anteriores ou posteriores, se os mesmos também não estivessem com esses erros. Se as falhas fossem de um período de tempo maior que três dias, realizavase uma média entre os três mesmos meses de anos anteriores ou posteriores, conforme cada caso específico. De forma análoga, analisou-se para as séries anuais. Se ocorressem falhas de três anos ou mais, eliminar-se-iam os dados anteriores a essas falhas, restando uma série de período menor que a original, porém de maior consistência de dados para serem tratados estatisticamente. No entanto, esses procedimentos não foram aplicados às observações de precipitações, em particular nos períodos úmidos. Dessa maneira, cada localidade tratada apresentou um período de estudo diferenciado, como fica evidenciado na última coluna das Tabelas 1 e 2 .
Nas Tabelas 3 e 4 encontram-se as características das séries anuais utilizadas neste estudo, observadas nas estações da ANA e do INMET, respectivamente. Nessas tabelas destacam-se, para cada estação medidora, os valores mínimo, máximo, médio e o desvio padrão de cada série temporal. Diante de todas as informações contidas nessas tabelas, chamam atenção os índices médios de chuvas (Tabela 4) que estão entre 513,69 $\pm 153,85$ mm _em Petrolina (PE), na região do SMSF_e $1427,39 \pm 229,87$ mm _em Bambuí (MG), na região do ASF-_, assim como as vazões médias anuais (Tabela 3) que se encontram entre os valores 8,67 $\pm 2,30 \mathrm{~m}^{3} \mathrm{~s}^{-1}$ _em Vargem Bonita (MG),

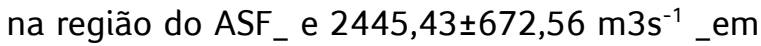
Ibotirama (BA), na região do MSF. De acordo com Haas e Guetter (2003), a bacia do São Francisco foi caracterizada por uma redução das vazões médias entre o período de 1972-1998, embora a diferença não tenha sido significativa, com 95\% de confiança, nos postos analisados por esses autores.

Tabela 3 - Características das séries de vazões médias anuais utilizadas neste estudo para medidas observadas pela ANA.

\begin{tabular}{|c|c|c|c|c|c|}
\hline$\#$ & Estação & Mínimo & Máximo & Médio & Desvio-padrão \\
\hline 1 & Vargem Bonita (MG) & 5,311 & 15,276 & 8,668 & 2,303 \\
\hline 2 & Iguatama (MG) & 50,408 & 228,275 & 106,823 & 31,359 \\
\hline 3 & Moema (MG) & 89,656 & 375,417 & 174,341 & 51,499 \\
\hline 4 & Abaeté (MG) & 98,342 & 472,083 & 228,730 & 70,699 \\
\hline 5 & Três Marias (MG) & 351,163 & 1677,485 & 675,705 & 227,007 \\
\hline 6 & Buritizeiro (MG) & 655,552 & 2173,215 & 1183,352 & 271,352 \\
\hline 7 & Pirapora (MG) & 420,180 & 1956,178 & 846,779 & 271,820 \\
\hline 8 & São Romão (MG) & 818,646 & 3448,453 & 1610,885 & 515,417 \\
\hline 9 & São Francisco (MG) & 930,045 & 3992,975 & 1945,673 & 617,311 \\
\hline 10 & Pedras M. da Cruz (MG) & 1083,772 & 3934,285 & 2058,894 & 601,310 \\
\hline 11 & Manga (MG) & 985,502 & 3732,005 & 2007,877 & 595,188 \\
\hline 12 & Carinhanha (BA) & 1073,755 & 4056,296 & 2184,211 & 648,812 \\
\hline 13 & Bom Jesus Lapa (BA) & 1136,756 & 4032,583 & 2170,604 & 624,765 \\
\hline 14 & Sítio do Mato (BA) & 1330,599 & 4312,236 & 2415,220 & 652,444 \\
\hline 15 & Paratinga (BA) & 1282,541 & 4355,235 & 2438,230 & 723,003 \\
\hline 16 & Ibotirama (BA) & 1326,386 & 4410,395 & 2445,433 & 672,562 \\
\hline 17 & Morpará (BA) & 1371,968 & 4343,778 & 2364,898 & 666,500 \\
\hline 18 & Juazeiro (BA) & 1516,719 & 4624,743 & 2445,004 & 741,083 \\
\hline 19 & Sta. Maria B. Vista (PE) & 1504,150 & 4676,668 & 2321,408 & 795,193 \\
\hline 20 & Belém S. Francisco (PE) & 1504,738 & 4686,035 & 2358,986 & 788,473 \\
\hline 21 & Piranhas (AL) & 1312,810 & 4437,178 & 2162,061 & 838,566 \\
\hline 22 & Pão de Açúcar (AL) & 1334,871 & 4574,475 & 2343,528 & 754,566 \\
\hline 23 & Traipu (AL) & 1568,839 & 4833,629 & 2441,025 & 861,327 \\
\hline 24 & Propriá (SE) & 1416,885 & 4515,751 & 2318,219 & 753,838 \\
\hline
\end{tabular}

Tabela 4 - Características das séries climáticas anuais utilizadas neste estudo para cada variável observada pelo INMET. 


\begin{tabular}{|c|c|c|c|c|c|c|}
\hline$\#$ & Cidade & Série & Mínimo & Máximo & Médio & Desvio-padrão \\
\hline \multirow{4}{*}{ A } & \multirow{4}{*}{ Bambuí (MG) } & T-Mín. & 13,709 & 16,323 & 14,638 & 0,518 \\
\hline & & T-Méd. & 19,773 & 22,842 & 21,636 & 0,522 \\
\hline & & T-Máx. & 27,754 & 29,768 & 28,764 & 0,466 \\
\hline & & Precip. & 970,500 & 2046,700 & 1427,391 & 229,871 \\
\hline \multirow{4}{*}{ B } & \multirow{4}{*}{ Bom Despacho (MG) } & T-Mín. & 13,471 & 17,169 & 15,592 & 1,334 \\
\hline & & T-Méd. & 21,702 & 23,563 & 22,634 & 0,508 \\
\hline & & T-Máx. & 28,381 & 31,059 & 29,680 & 0,701 \\
\hline & & Precip. & 892,900 & 1831,200 & 1367,670 & 238,616 \\
\hline \multirow{4}{*}{ C } & \multirow{4}{*}{ Pompéu (MG) } & T-Mín. & 14,971 & 18,319 & 16,619 & 0,747 \\
\hline & & T-Méd. & 21,733 & 24,372 & 23,081 & 0,633 \\
\hline & & T-Máx. & 28,202 & 30,900 & 29,460 & 0,684 \\
\hline & & Precip. & 820,500 & 1717,000 & 1240,389 & 215,147 \\
\hline \multirow{4}{*}{$\mathrm{D}$} & \multirow{4}{*}{ Pirapora (MG) } & T-Mín. & 16,406 & 19,295 & 18,170 & 0,679 \\
\hline & & T-Méd. & 22,758 & 25,720 & 24,511 & 0,639 \\
\hline & & T-Máx. & 29,111 & 32,214 & 30,876 & 0,697 \\
\hline & & Precip. & 515,556 & 2707,367 & 1095,945 & 359,905 \\
\hline \multirow{4}{*}{$\mathrm{E}$} & \multirow{4}{*}{ Januária (MG) } & T-Mín. & 17,507 & 19,102 & 18,282 & 0,345 \\
\hline & & T-Méd. & 24,048 & 29,833 & 25,085 & 1,011 \\
\hline & & T-Máx. & 29,372 & 32,805 & 31,362 & 0,739 \\
\hline & & Precip. & 538,559 & 1564,600 & 952,797 & 232,477 \\
\hline \multirow{4}{*}{$\mathrm{F}$} & \multirow{4}{*}{ Carinhanha (BA) } & T-Mín. & 17,818 & 20,652 & 19,480 & 0,681 \\
\hline & & T-Méd. & 24,421 & 26,986 & 25,797 & 0,621 \\
\hline & & T-Máx. & 31,734 & 33,319 & 32,382 & 0,453 \\
\hline & & Precip. & 307,200 & 1121,900 & 764,312 & 191,079 \\
\hline \multirow{4}{*}{ G } & \multirow{4}{*}{ Bom Jesus da Lapa (BA) } & T-Mín. & 18,556 & 20,930 & 20,017 & 0,511 \\
\hline & & T-Méd. & 25,531 & 27,323 & 26,416 & 0,457 \\
\hline & & T-Máx. & 31,027 & 33,818 & 32,590 & 0,615 \\
\hline & & Precip. & 457,300 & 1150,000 & 787,161 & 182,297 \\
\hline \multirow{4}{*}{$\mathrm{H}$} & & T-Mín. & 19,242 & 20,930 & 20,134 & 0,425 \\
\hline & & T-Méd. & 25,700 & 27,667 & 26,782 & 0,432 \\
\hline & Barra (BA) & T-Máx. & 32,143 & 34,404 & 33,373 & 0,526 \\
\hline & & Precip. & 288,800 & 895,500 & 653,829 & 164,555 \\
\hline & & T-Mín. & 20,507 & 23,014 & 21,740 & 0,591 \\
\hline 1 & Domonge (PA) & T-Méd. & 26,143 & 27,961 & 26,959 & 0,385 \\
\hline 1 & Remanso (BA) & T-Máx. & 30,336 & 34,736 & 32,030 & 0,384 \\
\hline & & Precip. & 188,500 & 2546,000 & 690,787 & 310,452 \\
\hline & & T-Mín. & 20,698 & 23,017 & 21,949 & 0,532 \\
\hline & & T-Méd. & 25,881 & 29,198 & 27,103 & 0,534 \\
\hline J & Petrolina (PE) & T-Máx. & 30,747 & 36,468 & 32,212 & 0,846 \\
\hline & & Precip. & 141,100 & 944,400 & 513,689 & 153,851 \\
\hline & & T-Mín. & 19,707 & 23,055 & 21,624 & 0,581 \\
\hline$k$ & Cabrobó (DE) & T-Méd. & 21,791 & 28,913 & 26,599 & 1,120 \\
\hline K & Cabrobo (PE) & T-Máx. & 30,231 & 33,518 & 31,930 & 0,684 \\
\hline & & Precip. & 134,000 & 2770,500 & 579,372 & 369,099 \\
\hline & & T-Mín. & 20,475 & 22,608 & 21,392 & 0,480 \\
\hline 1 & Dau Afarce (RA) & T-Méd. & 25,731 & 28,039 & 26,696 & 0,441 \\
\hline $\mathrm{L}$ & Paulo Afonso (BA) & T-Máx. & 30,781 & 33,469 & 32,002 & 0,516 \\
\hline & & Precip. & 190,600 & 2423,633 & 585,841 & 305,975 \\
\hline & & T-Mín. & 18,104 & 20,405 & 19,084 & 0,451 \\
\hline$M$ & Ácun Pronca (A) & T-Méd. & 23,059 & 25,270 & 23,727 & 0,423 \\
\hline$M$ & Agua Branca (AL) & T-Máx. & 27,333 & 30,135 & 28,406 & 0,520 \\
\hline & & Precip. & 471,000 & 1428,600 & 990,115 & 250,200 \\
\hline & & T-Mín. & 21,004 & 23,162 & 22,221 & 0,468 \\
\hline N & 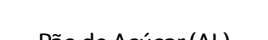 & T-Méd. & 26,480 & 28,972 & 27,947 & 0,433 \\
\hline $\mathrm{N}$ & Pao de Açucar (AL) & T-Máx. & 31,914 & 34,782 & 33,298 & 0,731 \\
\hline & & Precip. & 269,900 & 982,300 & 587,619 & 139,843 \\
\hline & & T-Mín. & 20,802 & 22,334 & 21,758 & 0,333 \\
\hline & & T-Méd. & 23,862 & 27,239 & 26,401 & 0,592 \\
\hline 0 & Propriá (SE) & T-Máx. & 30,471 & 32,179 & 31,124 & 0,362 \\
\hline & & Precip. & 633,000 & 1663,500 & 940,944 & 206,705 \\
\hline
\end{tabular}


De posse dos dados observados, os mesmos foram organizados e tratados em planilhas do aplicativo Microsoft Office Excel, o que possibilitou a realização dos cálculos visando detectar a ocorrência de uma tendência e a variabilidade dos parâmetros hidroclimáticos de interesse, além da geração de gráficos e a realização de análises estatísticas acuradas.

\subsection{Procedimentos e testes estatísticos utilizados}

Com o intuito de avaliar previamente o comportamento de série temporal anual associada a uma determinada variável, realizou-se o cálculo das médias móveis, empregando ordem cinco aos dados. Posteriormente, visando diminuir as influências de possíveis flutuações, trabalhou-se com a suavização dos dados usando a proposta vinculada por Sello (1999), aplicando a equação (1):

$$
\bar{V}_{n}=\frac{1}{6}\left[\sum_{i=n-2}^{n+2} V_{i}+\frac{1}{2}\left(V_{n+3}+V_{n-3}\right)\right] \text { Equação (1) }
$$

Nesta equação, $\left(\bar{V}_{n}\right)$ representa o valor médio de uma determinada variável em estudo para o i-ésimo ano $\left(V_{i}\right)$.

Em seguida, aplicou-se a análise de regressão linear aos pontos das médias móveis e suavizada, sendo em cada caso ajustada a linha de tendência da variável em análise. Nesse ajuste, calculado pelo método dos mínimos quadrados, considerou-se a série de dados pela variável $Y$ no tempo $t$, de forma que neste procedimento utilizou-se a equação da reta da tendência $(Y=a(x)+b)$, onde $x=t \quad \mathrm{e}$ " $a$ " $\mathrm{e}$ " $b$ " são os coeficientes angular $\mathrm{e}$ linear da reta ajustada, respectivamente. No caso de $a>0$ diz-se que a variabilidade é crescente; para $a<0$ a variabilidade é dita decrescente $\mathrm{e}$ quando $a \approx 0$ interpreta-se que não há variabilidade significativa no parâmetro trabalhado. Ao realizar esse procedimento para cada série temporal, o valor do poder do ajuste ( $R^{2}$ ) é calculado, além do intervalo de confiança (IC) em 95\% acima e abaixo do valor estimado do coeficiente angular da reta de regressão. De posse dos valores de IC de uma determinada série em análise, foi possível verificar se os coeficientes " $a$ " $\mathrm{e}$ " $b$ " foram determinados de forma correta e se " $a$ " é significativamente diferente de zero (FREUND, 2006).

Na sequência, empregou-se o teste não paramétrico de Mann-Kendall, que é utilizado para avaliar a significância de uma tendência (SNEYERS, 1975). Nesse teste considera-se que, na hipótese de estabilidade de uma série, a sucessão de valores ocorre de forma independente e a distribuição de probabilidade deve permanecer sempre a mesma (série aleatória simples). Assim, como descreveu Moraes et al. (1995), considerando uma série temporal $Y_{i}$ com $N$ termos, sendo $1 \leq i \leq N$, o procedimento consiste em realizar a soma $t_{n}$ do número de termos $m_{i}$ da série, relativo ao valor $Y_{i}$ cujos termos precedentes $(j<i)$ são inferiores ao mesmo $\left(Y_{j}<Y_{i}\right)$. Para séries com grande número de termos $(N)$, sob a hipótese nula $\left(H_{0}\right.$ ) de ausência de tendência, $t_{n}$ apresentará uma distribuição normal com média e variância dada, segundo Back (2001), respectivamente pelas equações (2) e (3):

$$
E\left(t_{n}\right)=\frac{N(N-1)}{4} \quad \text { Equação (2) }
$$

$\operatorname{Var}\left(t_{n}\right)=\frac{N(N-1)(2 N+5)}{72} \quad$ Equação (3)

Testando a significância estatística de $t_{n}$ para a hipótese nula, usando um teste bilateral, esta pode ser rejeitada para grandes valores da estatística $U\left(t_{n}\right)$, fornecida pela equação (4) (BACK, 2001): 
$U\left(t_{n}\right)=\frac{\left(t_{n}-E\left(t_{n}\right)\right)}{\sqrt{\operatorname{Var}\left(t_{n}\right)}}$

Equação (4)

O valor da probabilidade $\alpha_{1}$ é calculado por meio de uma tabela de distribuição normal reduzida, de forma que $\alpha_{1}=\operatorname{prob}\left(|U|>\mid U\left(t_{n}\right)\right)$. Sendo $\alpha_{0}$ o nível de significância do teste, a hipótese nula é aceita se $\alpha_{1}>\alpha_{0}$. Caso a hipótese nula seja rejeitada, implicará na existência de tendência significativa, com o sinal da estatística $U\left(t_{n}\right)$ indicando se a tendência é decrescente $\left(U\left(t_{n}\right)<0\right)$ ou então crescente $\left(U\left(t_{n}\right)>0\right)$.

O ponto de início de uma mudança na série pode ser estimado aplicando-se o mesmo princípio à série inversa. Assim, no sentido inverso da série temporal original, ao partir do valor $i=N$ até $i=1$, gera-se a estatística inversa $U^{*}\left(t_{n}\right)$. A intersecção das duas curvas estatísticas $U\left(t_{n}\right)$ e $U^{*}\left(t_{n}\right)$ corresponde ao ponto aproximado de mudança de tendência. Entretanto, isso só é significativo caso esse ponto ocorra dentro do intervalo de significância bilateral, isto é, entre $-1,65$ e $+1,96$, correspondentes a $\alpha_{0}=0,10$ (em 10\%) e $\alpha_{0}=0,05$ (em 5\%), respectivamente (BACK, 2001).

No teste de Pettitt, o procedimento adotado verifica se duas amostras $Y_{1}, Y_{2}, \ldots, Y_{t}$ e $Y_{t+1}, Y_{t+2}, \ldots, Y_{T}$ são provenientes de populações idênticas (PETTITT, 1979). A estatística $u_{(t, T)}$ faz uma contagem do número de vezes que um membro da primeira amostra é maior que um membro da segunda amostra, o que, de acordo com Moraes et al. (1995), pode ser escrito por meio da equação (5):

$u_{(t, T)}=u_{(t-1, T)}+\sum_{j=1}^{T} \operatorname{sgn}\left(Y_{i}-Y_{j}\right) \quad t=2, . ., T \quad$ Equação (5)

na qual: $\operatorname{sgn}(x)=1$ para $x>0 ; \operatorname{sgn}(x)=0$ para $x=0$ e $\operatorname{sgn}(x)=-1$ para $x<0$.
A partir dessa prerrogativa, a estatística $u_{(t, T)}$ é então calculada para valores de $1 \leq t \leq T$. Na sequência, obtém-se a estatística $K(t)$ calculando o máximo valor absoluto de $u_{(t, T)}$.É a estatística $K(t)$ que possibilita localizar o ponto em que houve a mudança brusca na média da série temporal. Para isso, segundo, o nível de significância é avaliado por intermédio da equação (6):

$$
p \cong 2 \cdot e^{\left(\frac{-6 \cdot K(t)^{2}}{\left(T^{3}-T^{2}\right)}\right)} \quad \text { Equação (6) }
$$

O ponto de mudança brusca é aquele no qual o valor de $t$ ocorre para o máximo (ou mínimo) valor de $K(t)$, obtido por meio da inversão da equação anterior, o que resulta na equação (7):

$K_{\text {crit. }}= \pm \sqrt{\frac{-\ln (p / 2) \cdot\left(T^{3}+T^{2}\right)}{6}}$ Equação (7)

Nesse teste, os níveis de significância da mudança foram calculados para $5 \%$ e $10 \%$ do valor de $K_{\text {crit. }}$. (BACK, 2001).

\section{RESULTADOS E DISCUSSÃO}

Optou-se por apresentar apenas alguns resultados em forma de gráficos exploratórios das séries temporais trabalhadas, visando à identificação de características e peculiaridades das mesmas, além da realização de interpretação estatística. Complementando esses gráficos, foram elaboradas tabelas que resumem as informações obtidas nas análises estatísticas de uma determinada variável climatológica ou hidrológica para cada localidade. Em seguida, baseadas nesses resultados, discussões são desencadeadas à luz dos possíveis processos que levaram às detecções de tendências. 


\subsection{Aplicações de testes paramétricos}

Como comentado anteriormente, com o intuito de avaliar apenas o comportamento de uma série temporal, primeiramente calcularam-se as médias móveis e a suavização dos dados. Dessa maneira foi possível realizar uma primeira análise de tendência com boa precisão, obtendo-se, por meio de gráficos, como os da Figura 2, os ajustes das médias móveis e suavizadas e as respectivas equações desses ajustes, além das determinações do coeficiente angular (a), dos seus intervalos de confiança (IC) e do poder do ajuste $\left(R^{2}\right)$ de cada série reduzida. Ao lado direito dos gráficos da Figura 2 encontram-se a equação da reta e o poder do ajuste, estando em cor vermelha as informações para o ajuste realizado com as médias móveis e em cor preta as médias suavizadas de cada série.

A Figura 2a mostra que a reta ajustada apresentou coeficiente angular positivo ( $a>0$ ), o que indica um aumento na T-mín. para a cidade de Pirapora (MG) entre 1961 e 2015, enquanto a reta ajustada na Figura $2 \mathrm{~b}$ revela um comportamento estável ( $a \approx 0$ ) do índice de T-máx. em Remanso (BA) entre 1961 e 2015. Verifica-se que a reta ajustada para o índice de Vaz. do rio São Francisco na localidade de Pão de Açúcar (AL) entre 1959 e 2015 acusou uma diminuição $(a<0)$, como pode ser constatado no gráfico da Figura 2c.

Da quarta à sexta coluna da Tabela 5 apresentam-se os resultados de todos os parâmetros ao aplicar o método da regressão linear usando os dados suavizados do levantamento realizado nas séries climáticas (T-mín., T-máx., T-méd. e Prec.). De forma análoga, da terceira à quinta coluna da Tabela 6 estão apresentados os ajustes dos dados hidrológicos (Vazão). Nessas colunas estão indicados os correspondentes valores de $(a)$, de $\left(R^{2}\right)$ e (IC-95\%). Como podem ser constatadas em ambas as tabelas, o valor do coeficiente angular ( $a$ ) para cada série temporal tratada está entre o mínimo e máximo do intervalo de confiança $(I C)$, indicando uma correta determinação desse coeficiente em cada caso abordado.

Respeitando o período da série temporal de cada localidade, uma análise da Tabela 5 revela que, entre as 15 estações trabalhadas do INMET, grande parte das séries acusou aumento ( $a>0$ ), sendo a T-máx., T-méd. e Prec. com dez casos cada. A T-mín. foi a grandeza que acusou maior número de ocorrências, com 12 registros. A quantidade de série temporal que acusou diminuição $(a<0)$ foi: T-mín., T-máx. e T-méd. com dois casos cada, enquanto a Prec. acusou cinco ocorrências. Para aqueles casos em que a grandeza não acusou variabilidade significativa ( $a \approx 0$ ) foram registrados: três casos para as T-máx. e T-méd., apenas um caso para a T-mín. e nenhum caso para Prec. Por outro lado, a Tabela 6 mostra que nos dados de Vaz., do total das 24 estações trabalhadas da ANA, apenas em quatro locais situados no estado de Minas Gerais foram registrados aumentos $(a>0)$ dessa grandeza (Iguatama; Abaeté; Três Marias e São Romão). Nas outras 20 localidades tratadas foram inferidas diminuições $(a<0)$ desse índice hidrológico.

Em relação à qualidade dos ajustes efetuados, quanto mais próximo da unidade o índice $R^{2}$, menor a dispersão dos dados e, consequentemente, melhor o ajuste efetuado. As informações contidas nas tabelas apresentaram um amplo intervalo de valores, estando entre 0,0001 (para T-méd. na cidade de Barra, BA) e 0,9700 (para T-mín. em Pirapora, MG), o que atesta a ampla diversificação dos dados aqui tratados. Quanto ao valor de IC, que indica a probabilidade do coeficiente angular de uma variável encontrar-se no intervalo inferior e superior calculado de $95 \%$ dos dados, os valores dependem da variável que está sendo tratada. Por conta disso há uma grande distribuição de intervalos de $I C$ revelados nas Tabelas 5 e 6 . 

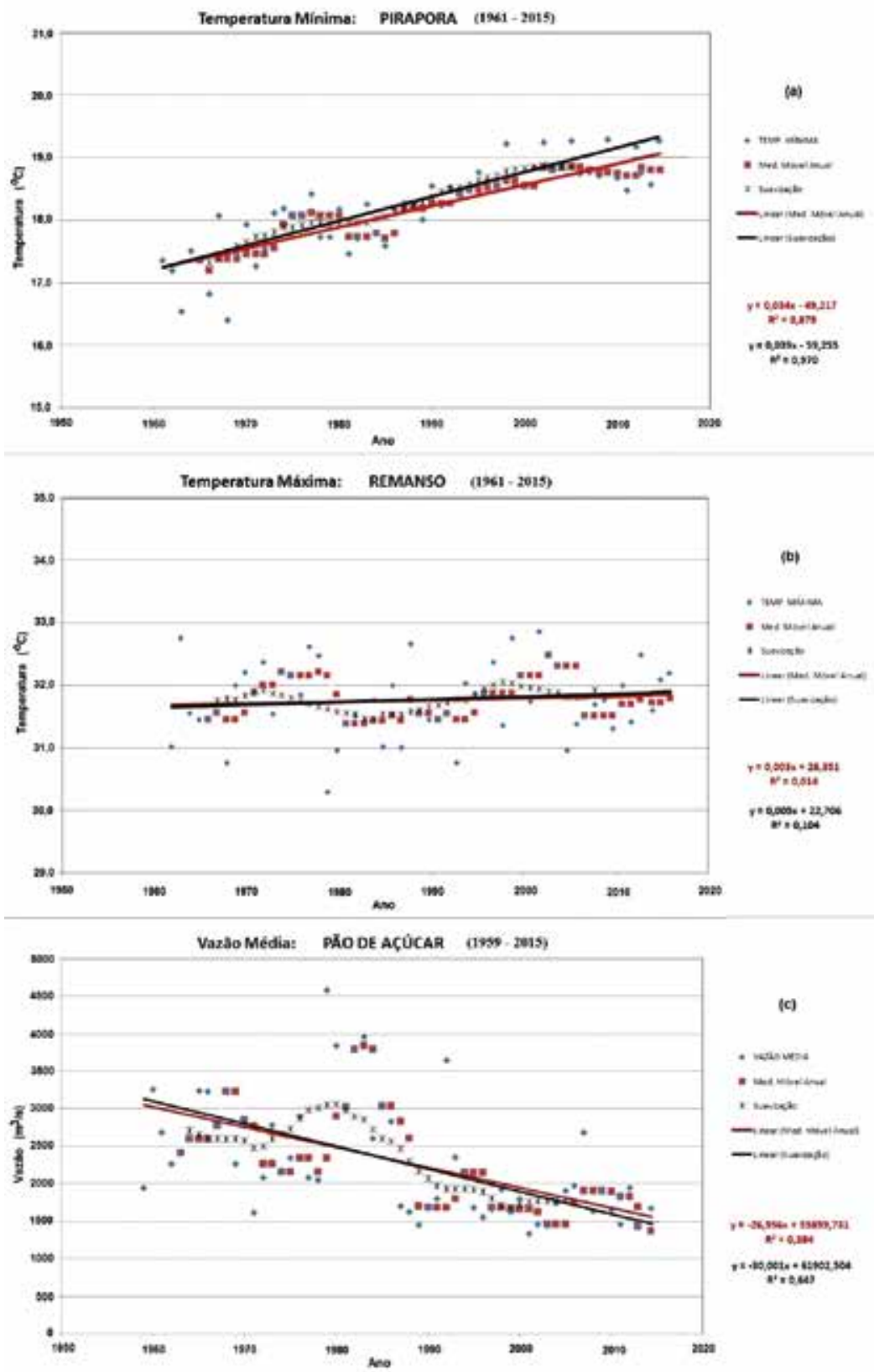

Figura 2 - Regressão linear aplicada às medições de: (a) T-mín. para Pirapora, MG; (b) T-máx. para Remanso, BA e (c) Vaz. do rio São Francisco na localidade de Pão de Açúcar, AL.

Embora as análises de regressão representem possibilidades de eventuais variabilidades das séries temporais tratadas, os intervalos de confiança empregados para esse tipo de análise tornam-se limitados. Portanto, torna-se inviável decidir se determinada série sofre ou não tendência, e a partir de quando isso passou a ocorrer. Por conta disso, empregaram-se os métodos estatísticos não paramétricos de Mann-Kendall e de Pettitt. 


\subsection{Aplicações de testes não paramétricos}

No tocante às aplicações dos testes não paramétricos, alguns exemplos de gráficos a eles relacionados são mostrados na Figura 3. Os gráficos dessa figura apresentam linhas horizontais tracejadas e pontiIhadas que indicam os intervalos (para o teste de Mann-Kendall) e os níveis (para o teste de Pettitt) de confiança de $\pm 5 \%$ a $\pm 10 \%$, respectivamente.

No teste de Mann-Kendall, uma tendência é dita significativa quando os valores absolutos de $U\left(t_{n}\right)$ são maiores que os intervalos de confiança e o início dessa tendência pode ser identificado pela intersecção das curvas $U\left(t_{n}\right)$ (em traçado contínuo) e $U^{*}\left(t_{n}\right)$ (em traçado pontiIhado), representadas na parte inferior dos gráficos da Figura 3. Isso, porém, deve ocorrer dentro dos valores críticos dos intervalos de confiança (SNEYERS, 1975). No entanto, no teste de Pettitt, que está apresentado na parte superior dos gráficos da mesma figura, como dito antes, o ponto de mudança brusca de $K(t)$, tomado em módulo, ocorre quando este for maior que os limites críticos estabelecidos de $5 \%$ e $10 \%$. Essa condição, porém, deixa de ser verdadeira quando os valores que estão em seguida ao valor crítico oscilam em intervalos próximos ao valor máximo. Nessa situação, o último valor do intervalo de oscilação indica o ponto de início da tendência (PETTITT, 1979).

Com a finalidade de estabelecer um critério que expresse os resultados dos dois testes em questão, utilizou-se a seguinte convenção: o sinal $(+)(+)$ para uma tendência positiva confirmada entre $5 \%$ e $10 \%$ dos níveis dos intervalos de confianças; o sinal (+) se for acima de $10 \%$ do nível do intervalo de confiança, de maneira análoga: os sinais (-)(-) e (-) para tendência negativa confirmada, respectivamente. Caso não houvesse condições de confirmar tendência, um sinal de interrogação (?) foi adotado para o teste empregado à série temporal. Essa convenção está contida nas Tabelas 5 e 6, onde estão apresentados os resultados inferidos após a aplicação dos testes estatísticos discutidos anteriormente.
Na sequência são apresentados e analisados na Figura 3 os casos dos comportamentos inferidos para os dados de três séries climáticas nas cidades de Cabrobó (PE), Bom Despacho (MG) e Propriá (AL).

Ao analisar o comportamento da T-mín. medida em Cabrobó, os testes de Mann-Kendall e Pettitt (Figura 3a) confirmam o registro de tendência positiva $(+)(+)$ a partir de 1997, pois as curvas estatísticas $U\left(t_{n}\right)$ e $U^{*}\left(t_{n}\right)$ cruzaram-se entre os intervalos de confianças nessa data e o ponto de mudança brusca da curva $K(t)$, ocorreu ao cruzar os limites críticos estabelecidos de $5 \%$ e $10 \%$ com $\quad K_{\text {crit. }}$. também em 1997. O comportamento da T-méd. (Figura 3b) para a cidade de Bom Despacho revelou uma tendência negativa (-)(-) a partir de 1997. Isso se verificou porque também as curvas $U\left(t_{n}\right)$ e $U^{*}\left(t_{n}\right)$ do teste de Mann-Kendall se cruzaram entre os intervalos de confianças na data de 1998, ao passo que o ponto de mudança brusca de $K(t)$ do teste de Pettitt ocorreu ao cruzar os limites críticos estabelecidos de 5\% e 10\% em 1997.

No entanto, esses mesmos testes não paramétricos aplicados à série de Prec. na cidade de Propriá não confirmaram tendência, como pode ser notado na Figura 3c. Nesse caso, ocorreram vários cruzamentos das curvas do teste de Mann-Kendall entre os intervalos de confiança e, além disso, a curva $K(t)$ de Pettitt em nenhum momento cruzou os limites críticos de $5 \%$ e $10 \%$, descartando qualquer possibilidade de tendência dessa série temporal.

Os gráficos da Figura 4 revelam os mesmos testes não paramétricos para as séries de vazão média anual no rio São Francisco. No gráfico inferior da Figura 4a é mostrado o comportamento do teste de Mann-Kendall aplicado à localidade de Morpará (BA), indicando vários cruzamentos das curvas estatísticas. Entretanto, a curva do teste de Pettitt (gráfico superior da Figura 4a) não cruzou os limites críticos estabelecidos de $5 \%$ e $10 \%$. Esses resultados indicam ausência de tendência significativa da vazão medida naquele local. 
Para as séries temporais das cidades de Juazeiro (BA) e Traipu (AL), Figura 4b e 4c, respectivamente, os gráficos resultantes da aplicação dos testes de Mann-Kendall e de Pettitt revelaram tendências negativas de nível (-)(-) confirmadas em ambas localidades. Essas tendências tornaram-se significativas a partir de 1986, pois em cada caso, ao aplicar o teste de Mann-Kendall, ocorreu uma intersecção das curvas $U\left(t_{n}\right)$ e $U^{*}\left(t_{n}\right)$ entre os níveis de significâncias de $\pm 5 \%$ a $\pm 10 \%$. Adicionalmente, a curva da estatística no teste de Pettitt também cruzou os níveis de significância de $\pm 5 \%$ a $\pm 10 \%$ do valor calculado para $K_{\text {crit. }}$, confirmando a ocorrência da "quebra" na série temporal em 1986.

Tabela 5 - Resultados das análises de regressão linear pela suavização dos dados e os testes não paramétricos inferidos para as variáveis climáticas medidas pelo INMET.

\begin{tabular}{|c|c|c|c|c|c|c|c|c|}
\hline$\#$ & Cidade & Série & a & $\mathbf{R}^{2}$ & IC (95\%) & Mann-Kendall & Pettitt & Tendência \\
\hline \multirow{4}{*}{ A } & \multirow{4}{*}{$\begin{array}{l}\text { Bambuí (MG) } \\
(1972-2015)\end{array}$} & T-Mín. & $+0,0213$ & 0,8360 & $+0,0176 /+0,0250$ & $(+)(+) 1993$ & $(+)(+) 1991$ & $(+)(+) 1991$ \\
\hline & & $(1972-2015)$ & $+0,0321$ & 0,8688 & $+0,0272 /+0,0371$ & $(+)(+) 1993$ & $(+)(+) 1992$ & $(+)(+) 1992$ \\
\hline & & T-Máx. & $+0,0299$ & 0,8768 & $+0,0255 /+0,0343$ & $(+)(+) 1993$ & $(+)(+) 1993$ & $(+)(+) 1993$ \\
\hline & & Precip. & $+6,5641$ & 0,7846 & $+5,2061 /+7,9221$ & $(+)(+) 2004$ & (?) & (?) \\
\hline \multirow{4}{*}{ B } & \multirow{4}{*}{$\begin{array}{c}\text { Bom Despacho (MG) } \\
(1981-2015)\end{array}$} & T-Mín. & $-0,1659$ & 0,9527 & $-0,1843 /-0,1477$ & $(-)(-) 1998$ & $(-)(-) 1997$ & $(-)(-) 1997$ \\
\hline & & $(1981-2015)$ & $-0,0536$ & 0,9266 & $-0,0610 /-0,0461$ & $(-)(-) 1998$ & $(-)(-) 1997$ & $(-)(-) 1997$ \\
\hline & & T-Máx. & $+0,0598$ & 0,9460 & $+0,0527 /+0,0669$ & $(+)(+) 1996$ & $(+)(+) 1997$ & $(+)(+) 1997$ \\
\hline & & Precip. & $+2,0424$ & 0,2719 & $+0,3876 /+3,6972$ & $(?)$ & (?) & $(?)$ \\
\hline \multirow{4}{*}{ C } & \multirow{4}{*}{$\begin{array}{l}\text { Pompéu (MG) } \\
\text { (1972-2015) }\end{array}$} & T-Mín. & $+0,0545$ & 0,9452 & $+0,0493 /+0,0597$ & $(+)(+) 1993$ & $(+)(+) 1993$ & $(+)(+) 1993$ \\
\hline & & $(1972-2015)$ & $+0,0462$ & 0,9485 & $+0,0419 /+0,0505$ & (+)1996 & $(+)(+) 1993$ & $(+)(+) 1993$ \\
\hline & & T-Máx. & $+0,0417$ & 0,9636 & $+0,0385 /+0,0449$ & (?) & $(+)(+) 1992$ & (?) \\
\hline & & Precip. & $+1,5122$ & 0,0522 & $-1,0309 /+4,0553$ & (?) & (?) & (?) \\
\hline \multirow{4}{*}{ D } & \multirow{4}{*}{$\begin{array}{l}\text { Pirapora (MG) } \\
(1961-2015)\end{array}$} & T-Mín. & $+0,0390$ & 0,9700 & $+0,0368 /+0,0413$ & (?) & $(+)(+) 1989$ & (?) \\
\hline & & (1961-2015) & $+0,0393$ & 0,9338 & $+0,0359 /+0,0427$ & $(+) 1988$ & $(+)(+) 1985$ & $(+)(+) 1985$ \\
\hline & & T-Máx. & $+0,0382$ & 0,8704 & $+0,0334 /+0,0431$ & $(+)(+) 1992$ & $(+)(+) 1992$ & $(+)(+) 1992$ \\
\hline & & Precip. & $-1,3874$ & 0,0637 & $-3,1336 /+0,3589$ & (?) & (?) & (?) \\
\hline \multirow{4}{*}{$E$} & \multirow{4}{*}{$\begin{array}{l}\text { Januária (MG) } \\
(1976-2015)\end{array}$} & T-Mín. & $+0,0134$ & 0,8276 & $+0,0107 /+0,0160$ & $(+)(+) 1985$ & (?) & (?) \\
\hline & & $(1976-2015)$ & $+0,0225$ & 0,6151 & $+0,0148 /+0,0302$ & $(+)(+) 1995$ & (+)1992 & $(+) 1992$ \\
\hline & & T-Máx. & $+0,0500$ & 0,9490 & $+0,0450 /+0,0550$ & $(+)(+) 1993$ & $(+)(+) 1992$ & $(+)(+) 1992$ \\
\hline & & Precip. & $-0,1709$ & 0,0013 & $-2,2089 /+1,8670$ & $(+)(+) 1984$ & (?) & (?) \\
\hline \multirow{4}{*}{$\mathrm{F}$} & \multirow{4}{*}{$\begin{array}{l}\text { Carinhanha (BA) } \\
(1977-2015)\end{array}$} & T-Mín. & $+0,0486$ & 0,8412 & $+0,0335 /+0,0672$ & $(+)(+) 2009$ & (?) & (?) \\
\hline & & $(1977-2015)$ & $+0,0304$ & 0,7325 & $+0,0146 /+0,0547$ & $(+)(+) 1994$ & $(+)(+) 1994$ & $(+)(+) 1994$ \\
\hline & & T-Máx. & $-0,0182$ & 0,8501 & $-0,0232 /-0,0126$ & (?) & (?) & (?) \\
\hline & & Precip. & $+7,8403$ & 0,6848 & $+3,5382 /+13,2716$ & $(+)(+) 1994$ & (?) & (?) \\
\hline \multirow{4}{*}{ G } & \multirow{4}{*}{$\begin{array}{c}\text { Bom Jesus da Lapa } \\
\text { (BA) } \\
(1986-2015)\end{array}$} & T-Mín. & $+0,0204$ & 0,7388 & $+0,0121 /+0,0277$ & $(+)(+) 1994$ & $(+)(+) 1994$ & $(+)(+) 1994$ \\
\hline & & $(1986-2015)$ & $+0,0156$ & 0,8049 & $+0,0110 /+0,0202$ & (?) & (?) & (?) \\
\hline & & T-Máx. & $+0,01883$ & 0,7079 & $+0,0116 /+0,0261$ & (?) & (?) & (?) \\
\hline & & Precip. & $+1,3838$ & 0,1073 & $-1,0068 /+3,7743$ & (?) & (?) & (?) \\
\hline \multirow{4}{*}{$\mathrm{H}$} & \multirow{4}{*}{$\begin{array}{c}\text { Barra (BA) } \\
(1986-2015)\end{array}$} & T-Mín. & $+0,0120$ & 0,6369 & $+0,0066 /+0,0175$ & $(+)(+) 2008$ & (?) & (?) \\
\hline & & (1986-2015) & $-0,0001$ & 0,0001 & $-0,0079 /+0,0077$ & $(-)(-) 1994$ & (?) & (?) \\
\hline & & T-Máx. & $-0,0013$ & 0,0089 & $-0,0093 /+0,0067$ & (?) & (?) & (?) \\
\hline & & Precip. & $+4,2145$ & 0,5482 & $+1,9219 /+6,5071$ & (?) & (?) & (?) \\
\hline \multirow{4}{*}{1} & \multirow{4}{*}{$\begin{array}{l}\text { Remanso (BA) } \\
(1961-2015)\end{array}$} & T-Mín. & $+0,0231$ & 0,8879 & $+0,0204 /+0,0257$ & (?) & $(+)(+) 1987$ & (?) \\
\hline & & $(1961-2015)$ & $+0,0067$ & 0,3885 & $+0,0039 /+0,0094$ & $(+)(+) 2004$ & $+)(+) 1997$ & (?) \\
\hline & & T-Máx. & $+0,0046$ & 0,1042 & $+0,0002 /+0,0089$ & $(?)$ & $(-)(-) 1984$ & (?) \\
\hline & & Precip. & $-6,7890$ & 0,7555 & $-8,0581 /-5,5211$ & $(-)(-) 1985$ & $(-)(-) 1983$ & $(-)(-) 1983$ \\
\hline \multirow{4}{*}{ J } & \multirow{4}{*}{$\begin{array}{l}\text { Petrolina (PE) } \\
(1963-2015)\end{array}$} & T-Mín. & $+0,0287$ & 0,8861 & $+0,0409 /+0,0072$ & $(+)(+) 1989$ & $(+)(+) 1984$ & (?) \\
\hline & & $(1963-2015)$ & $+0,0226$ & 0,9384 & $-0,0014 /+0,0427$ & (?) & $(+)(+) 1979$ & (?) \\
\hline & & T-Máx. & $+0,0211$ & 0,8099 & $+0,0447 /+0,0069$ & $(+)(+) 1987$ & $(+)(+) 1984$ & $(+)(+) 1984$ \\
\hline & & Precip. & $-0,1577$ & 0,0147 & $-0,1876 /-0,1279$ & $(-)(-) 1984$ & $(-)(-) 1984$ & $(-)(-) 1984$ \\
\hline \multirow{4}{*}{$\mathrm{K}$} & \multirow{4}{*}{$\begin{array}{l}\text { Cabrobó (PE) } \\
(1961-2015)\end{array}$} & T-Mín. & $+0,0226$ & 0,9027 & $+0,0202 /+0,0251$ & $(+)(+) 1997$ & $(+)(+) 1997$ & $(+)(+) 1997$ \\
\hline & & (1961-2015) & $+0,0294$ & 0,9115 & $+0,0264 /+0,0324$ & (?) & $(+)(+) 1982$ & (?) \\
\hline & & T-Máx. & $+0,0298$ & 0,9155 & $+0,0268 /+0,0328$ & (?) & $(+)(+) 1981$ & (?) \\
\hline & & Precip. & $+1,5695$ & 0,0847 & $-3,2640 /+0,4251$ & (?) & (?) & (?) \\
\hline
\end{tabular}


Tabela 5 - Resultados das análises de regressão linear pela suavização dos dados e os testes não paramétricos inferidos para as variáveis climáticas medidas pelo INMET. (continuação)

\begin{tabular}{|c|c|c|c|c|c|c|c|c|}
\hline$\#$ & Cidade & Série & a & $\mathbf{R}^{2}$ & IC (95\%) & Mann-Kendall & Pettitt & Tendência \\
\hline \multirow{4}{*}{$\mathrm{L}$} & \multirow{4}{*}{$\begin{array}{l}\text { Paulo Afonso (BA) } \\
\quad(1961-2015)\end{array}$} & T-Mín. & $+0,0277$ & 0,7897 & $+0,0230 /+0,0324$ & $(+)(+) 1981$ & $(+)(+) 1983$ & $(+)(+) 1983$ \\
\hline & & $(1961-2015)$ & $+0,0205$ & 0,8062 & $+0,0172 /+0,0238$ & $(+)(+) 1983$ & $(+)(+) 1983$ & $(+)(+) 1983$ \\
\hline & & T-Máx. & $+0,0138$ & 0,7886 & $+0,0115 /+0,0161$ & $(+)(+) 1984$ & $(+) 1983$ & $(+) 1983$ \\
\hline & & Precip. & $-7,6609$ & 0,7121 & $-9,2606 /-6,0614$ & $(-)(-) 1980$ & $(-)(-) 1986$ & (?) \\
\hline \multirow{4}{*}{ M } & \multirow{4}{*}{$\begin{array}{c}\text { Água Branca (AL) } \\
(1976-2015)\end{array}$} & T-Mín. & $+0,0122$ & 0,4873 & $+0,0068 /+0,0176$ & $(+)(+) 1980$ & $(+)(+) 1995$ & (?) \\
\hline & & (1976-2015) & $+0,0064$ & 0,0030 & $+0,0001 /+0,0120$ & $(+)(+) 1980$ & $(+) 1981$ & $(+) 1981$ \\
\hline & & T-Máx. & $-0,0014$ & 0,0029 & $-0,0122 /+0,0095$ & (?) & (?) & (?) \\
\hline & & Precip. & $+6,3119$ & 0,8219 & $+5,0444 /+7,5794$ & (?) & (?) & (?) \\
\hline \multirow{4}{*}{$\mathrm{N}$} & \multirow{4}{*}{$\begin{array}{l}\text { Pão de Açúcar (AL) } \\
\text { (1977-2015) }\end{array}$} & T-Mín. & $-0,0048$ & 0,1845 & $-0,0189 /-0,0092$ & (?) & $(+)(+) 1991$ & (?) \\
\hline & & $(1977-2015)$ & $-0,0114$ & 0,6887 & $-0,0221 /-0,0008$ & $(+)(+) 1980$ & (?) & (?) \\
\hline & & T-Máx. & $-0,0227$ & 0,7947 & $-0,0388 /-0,0067$ & $(+)(+) 1985$ & $(+)(+) 1986$ & $(+)(+) 1986$ \\
\hline & & Precip. & $+15,3336$ & 0,9478 & $+10,3375 /+20,3297$ & $(+) 2003$ & $(+) 2003$ & $(+) 2003$ \\
\hline \multirow{4}{*}{0} & \multirow{4}{*}{$\begin{array}{c}\text { Propriá (SE) } \\
(1977-2015)\end{array}$} & T-Mín. & $+0,0185$ & 0,9298 & $+0,0162 /+0,0208$ & $(+) 1987$ & $(+)(+) 1987$ & $(+)(+) 1987$ \\
\hline & & $(1977-2015)$ & $+0,0257$ & 0,7370 & $+0,0189 /+0,0325$ & $(+)(+) 1987$ & $(+)(+) 1987$ & $(+)(+) 1987$ \\
\hline & & & $+0,0252$ & 0,9436 & $+0,0225 /+0,0279$ & $(+) 1990$ & $(+)(+) 1996$ & (?) \\
\hline & & Precip. & $+9,2009$ & 0,8625 & $+7,5767 /+10,8250$ & $(+)(+) 1999$ & (?) & (?) \\
\hline
\end{tabular}

Tabela 6 - Resultados das análises de regressão linear pela suavização dos dados e os testes não paramétricos medidos para o índice de vazão em estações medidoras da ANA.

\begin{tabular}{|c|c|c|c|c|c|c|c|}
\hline$\#$ & Estação & a & $\mathbf{R}^{2}$ & IC (95\%) & Mann-Kendall & Pettitt & Tendência \\
\hline 1 & $\begin{array}{c}\text { Vargem Bonita (MG) } \\
(1954-2015)\end{array}$ & $-0,0247$ & 0,2942 & $-0,0362 /-0,0132$ & $(-)(-) 2001$ & (?) & (?) \\
\hline 2 & $\begin{array}{l}\text { Iguatama (MG) } \\
(1935-2015)\end{array}$ & $+0,1125$ & 0,0490 & $-0,0112 /+0,2362$ & (?) & (?) & (?) \\
\hline 3 & $\begin{array}{l}\text { Moema (MG) } \\
(1967-2015)\end{array}$ & $-1,1584$ & 0,3969 & $-1,6814 /-0,6353$ & $(-)(-) 1998$ & (?) & (?) \\
\hline 4 & $\begin{array}{l}\text { Abaeté (MG) } \\
(1958-2015)\end{array}$ & $+0,2798$ & 0,0458 & $-0,1231 /+0,6825$ & (?) & (?) & (?) \\
\hline 5 & $\begin{array}{c}\text { Três Marias (MG) } \\
(1957-2015)\end{array}$ & $+0,3039$ & 0,0015 & $-2,3859 /+2,9937$ & (?) & (?) & (?) \\
\hline 6 & $\begin{array}{c}\text { Buritizeiro (MG) } \\
(1959-2015)\end{array}$ & $-1,0461$ & 0,0169 & $-3,5929 /+1,5006$ & $(?)$ & $(?)$ & (?) \\
\hline 7 & $\begin{array}{l}\text { Pirapora (MG) } \\
(1968-2015)\end{array}$ & $-5,8842$ & 0,3552 & $-8,7885 /-2,9800$ & $(?)$ & $(+) 1977$ & (?) \\
\hline 8 & $\begin{array}{l}\text { São Romão (MG) } \\
\text { (1953-2015) }\end{array}$ & $+2,1200$ & 0,0202 & $-2,2599 /+6,4999$ & $(-)(-) 1999$ & $(+) 1977$ & $(?)$ \\
\hline 9 & $\begin{array}{l}\text { São Francisco (MG) } \\
(1935-2015)\end{array}$ & $-3,2265$ & 0,0600 & $-6,4148 /-0,0379$ & (?) & (?) & $(?)$ \\
\hline 10 & $\begin{array}{c}\text { Pedras M. da Cruz (MG) } \\
(1973-2015)\end{array}$ & $-27,9938$ & 0,8239 & $-33,2109 /-22,7768$ & (?) & (?) & $(?)$ \\
\hline 11 & $\begin{array}{l}\text { Manga (MG) } \\
(1937-2015)\end{array}$ & $-3,1140$ & 0,0675 & $-6,0529 /-0,1753$ & (?) & (?) & $(?)$ \\
\hline 12 & $\begin{array}{c}\text { Carinhanha (BA) } \\
(1932-2015)\end{array}$ & $-6,1509$ & 0,2013 & $-9,1384 /-3,1636$ & (?) & (?) & $(?)$ \\
\hline 13 & $\begin{array}{c}\text { Bom Jesus Lapa (BA) } \\
(1941-2015)\end{array}$ & $-0,5391$ & 0,0015 & $-4,2292 /+3,1509$ & $(+)(+) 1949$ & (?) & (?) \\
\hline 14 & $\begin{array}{c}\text { Sítio do Mato (BA) } \\
(1969-2015)\end{array}$ & $-31,1199$ & 0,7522 & $-37,7799 /-24,4598$ & $(-)(-) 1992$ & $(-)(-) 1986$ & (?) \\
\hline 15 & $\begin{array}{c}\text { Paratinga (BA) } \\
(1977-2015)\end{array}$ & $-37,4491$ & 0,7804 & $-46,2317 /-28,6665$ & $(-)(-) 1986$ & $(-)(-) 1986$ & $(-)(-) 1986$ \\
\hline 16 & $\begin{array}{l}\text { Ibotirama (BA) } \\
(1954-2015)\end{array}$ & $-11,5589$ & 0,2274 & $-17,9550 /-5,1629$ & $(-)(-) 1995$ & $(-)(-) 1986$ & (?) \\
\hline 17 & $\begin{array}{l}\text { Morpará (BA) } \\
(1954-2015)\end{array}$ & $-6,5135$ & 0,0927 & $-12,6318 /-0,3951$ & $(-)(-) 1991$ & (?) & $(?)$ \\
\hline 18 & $\begin{array}{l}\text { Juazeiro (BA) } \\
(1932-2015)\end{array}$ & $-12,8478$ & 0,4898 & $-16,0453 /-9,6504$ & $(-)(-) 1986$ & $(-)(-) 1986$ & $(-)(-) 1986$ \\
\hline 19 & $\begin{array}{c}\text { Sta. Maria B. Vista (PE) } \\
(1977-2015)\end{array}$ & $-45,1980$ & 0,8508 & $-53,5659 /-36,8301$ & $(-)(-) 1986$ & $(-)(-) 1986$ & $(-)(-) 1986$ \\
\hline 20 & $\begin{array}{c}\text { Belém S. Francisco (PE) } \\
(1977-2015)\end{array}$ & $-43,6119$ & 0,7992 & $-53,2784 /-33,9454$ & $(-)(-) 1986$ & $(-)(-) 1986$ & $(-)(-) 1986$ \\
\hline 21 & $\begin{array}{l}\text { Piranhas (AL) } \\
(1979-2015)\end{array}$ & $-39,2619$ & 0,7466 & $-49,9310 /-28,5928$ & $(-)(-) 1983$ & $(-)(-) 1986$ & $(-)(-) 1986$ \\
\hline 22 & $\begin{array}{l}\text { Pão de Açúcar (AL) } \\
\text { (1959-2015) }\end{array}$ & $-30,0009$ & 0,6470 & $-37,0819 /-22,9198$ & $(-)(-) 1987$ & $(-)(-) 1986$ & $(-)(-) 1986$ \\
\hline 23 & $\begin{array}{l}\text { Traipu (AL) } \\
(1977-2015)\end{array}$ & $-50,7872$ & 0,7910 & $-62,3286 /-39,2458$ & $(-)(-) 1985$ & $(-)(-) 1986$ & $(-)(-) 1986$ \\
\hline 24 & $\begin{array}{l}\text { Propriá (SE) } \\
(1977-2015)\end{array}$ & $-41,1339$ & 0,7908 & $-50,4884 /-31,7795$ & $(-)(-) 1985$ & $(-)(-) 1986$ & $(-)(-) 1986$ \\
\hline
\end{tabular}



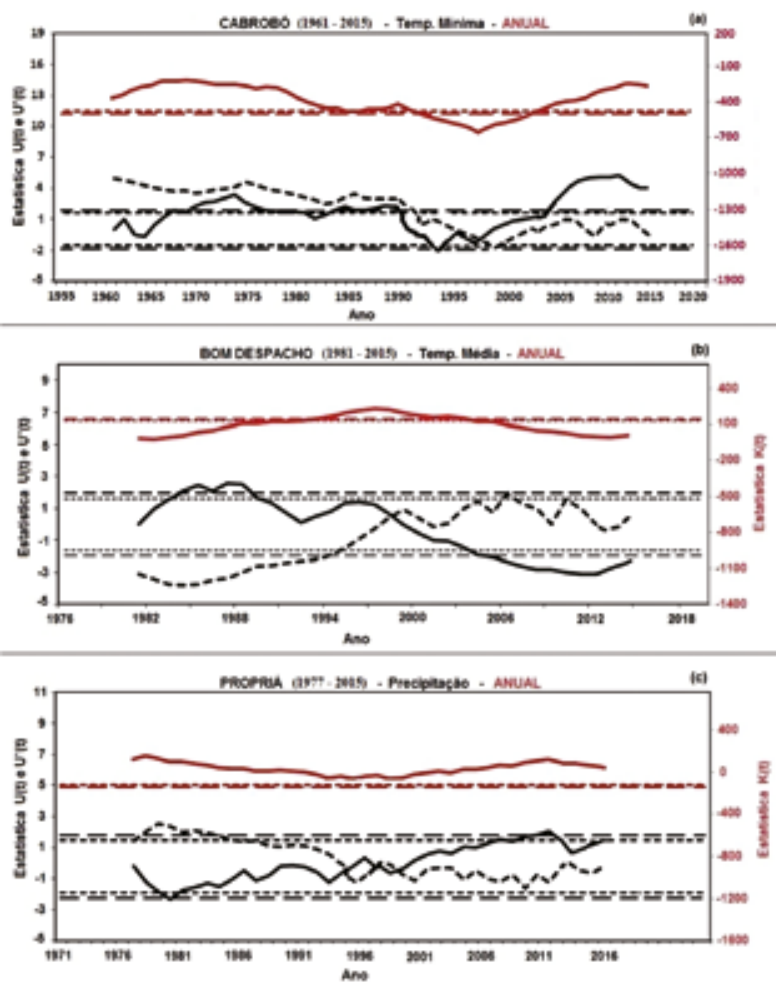

Figura 3 -Estatísticas de Mann-Kendall (inferior e em preto) e Pettitt (superior em vermelho) para as localidades: (a) Cabrobó, PE; (b) Bom Despacho, MG e (c) Propriá, AL.
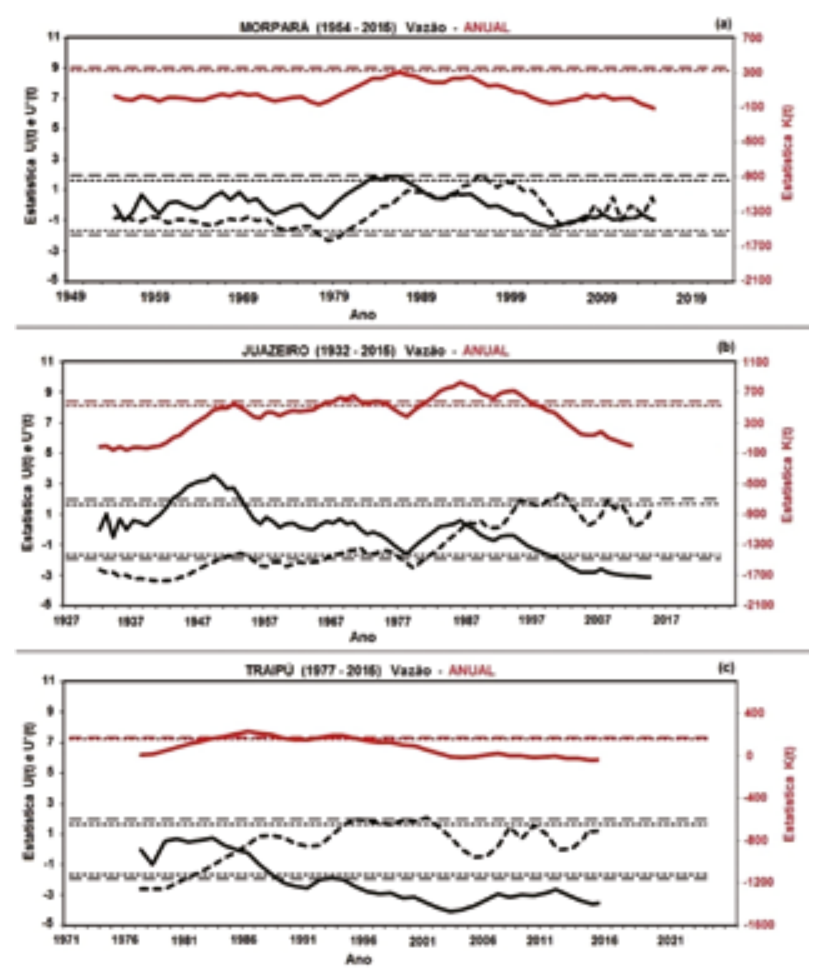

Figura 4 -Estatísticas de Mann-Kendall (inferior e em preto) e Pettitt (superior em vermelho) para as localidades: (a) Morpará, BA; (b) Juazeiro, BA e (c) Traipu, AL. 


\subsection{Mapas de tendências hidroclimáticas}

No intuito de detalhar os resultados obtidos, levando-se em consideração todas as localidades analisadas ao longo do rio São Francisco pelos testes não paramétricos, decidiu-se elaborar mapas relativos às distribuições de tendências, que estão mostrados na Figura 5, para cada variável tratada. Como comentado antes, é relevante destacar que a maior parte da região onde se localiza a bacia do São Francisco é semiárida (MMA, 2006), apresentando temperaturas elevadas durante todo o ano, pequena variação térmica (entre $2^{\circ} \mathrm{C}$ e $3^{\circ} \mathrm{C}$ ) e baixos índices pluviométricos (inferiores a $900 \mathrm{~mm}$ anuais).

Nas Figuras $5 a, 5 b$ e 5 c encontram-se as distribuições de tendências das temperaturas, onde se percebe que algumas cidades apresentam tendências crescentes $(+)(+)$, sendo identificados: seis casos para T-mín. (40,0\%); oito casos para T-méd. (53,0\%) e sete casos para T-máx. (47,0\%). Para tendência positiva (+), dois casos (Januária, MG, e Água Branca, $\mathrm{AL}$ ) foram identificados na $T$-méd., e somente um caso (Paulo Afonso, BA) foi encontrado na T-máx. Tendências negativas com nível (-)(-) para as T-mín. e T-méd. foram registradas em Bom Despacho (MG).

A Figura $5 d$ revela que duas cidades, Petrolina (PE) e Pão de Açúcar ( $\mathrm{AL}$ ), apresentaram tendência positiva $(+)(+)$ e (+), respectivamente, na variável Prec., o que corresponde a $13,0 \%$ do total de localidades analisadas. Apenas a cidade baiana de Remanso acusou tendências negativas no índice de chuvas com nível $(-)(-)$, correspondendo a 7\% das estações do INMET aqui tratadas. Todos os outros 12 municípios não registraram quaisquer indícios de tendências na Prec. nos períodos tratados.

A situação hidrológica revela-se bem diferente da climática, como pode ser testemunhado pela espacialização das tendências dos índices de vazão no vale do rio São Francisco, mostrada na Figura 5e. Não obstante, existem nesse vale usinas hidrelétricas em operação, de montante para jusante, a saber: Três Marias; Sobradinho; Itaparica (Luis Gonzaga); Moxotó
(Apolônio Sales); Paulo Afonso 1, 2 e 3; Paulo Afonso 4 e Xingó. Como comentado anteriormente, dessas usinas apenas Três Marias, Sobradinho e Itaparica possuem reservatórios de regularização para controle dos recursos hídricos das diferentes regiões por onde percorre o rio São Francisco (Codevasf, 2015).

Examinando em detalhes a Figura 5e, assim como as medições contidas na Tabela 6, pode-se destacar que não houve ocorrência de tendência no índice de vazão ao longo do rio desde a nascente até a Eclusa de Sobradinho, com exceção dos dados medidos no município de Paratinga (BA), que acusaram tendência negativa (-)(-) a partir de 1986. Após a referida barragem, isto é, distante cerca de $40 \mathrm{~km}$ a montante das cidades de Juazeiro (BA) e Petrolina (PE), registrou-se tendência negativa $(-)(-)$ em todas as sete estações medidoras da ANA aqui avaliadas estatisticamente a partir de 1986.

Os resultados aqui apresentados não são meras coincidências e requerem uma avaliação mais aprofundada das suas causas. Em princípio, pode-se julgar que a referida barragem teve influência sobre o fluxo d'água do rio, como também foi identificado por Martins et al. (2011), no estudo sobre o impacto causado pela usina hidroelétrica de Sobradinho.

Com extensão aproximada de $320 \mathrm{~km}$, uma superfície de espelho d'água de $4.214 \mathrm{~km}^{2}$ e uma capacidade de armazenamento de 34,1 bilhões de $\mathrm{m}^{3}$ na cota máxima operativa normal de 392,5 m, a Barragem de Sobradinho teve a conclusão das obras e o enchimento do reservatório em 1979, constituindo a partir de então um grande lago artificial no sertão nordestino, o que garante, juntamente com o Reservatório de Três Marias, uma vazão regularizada de $2.060 \mathrm{~m}^{3} \mathrm{~s}^{-1}$ em períodos de estiagem. A partir de março de 1982, com a entrada em operação de todas as turbinas da usina para atingir a potência global, juntamente com o início de operação da eclusa para a navegação fluvial, após nove anos, o Reservatório de Sobradinho consolida sua concepção inicial (MARTINS et al., 2011). 


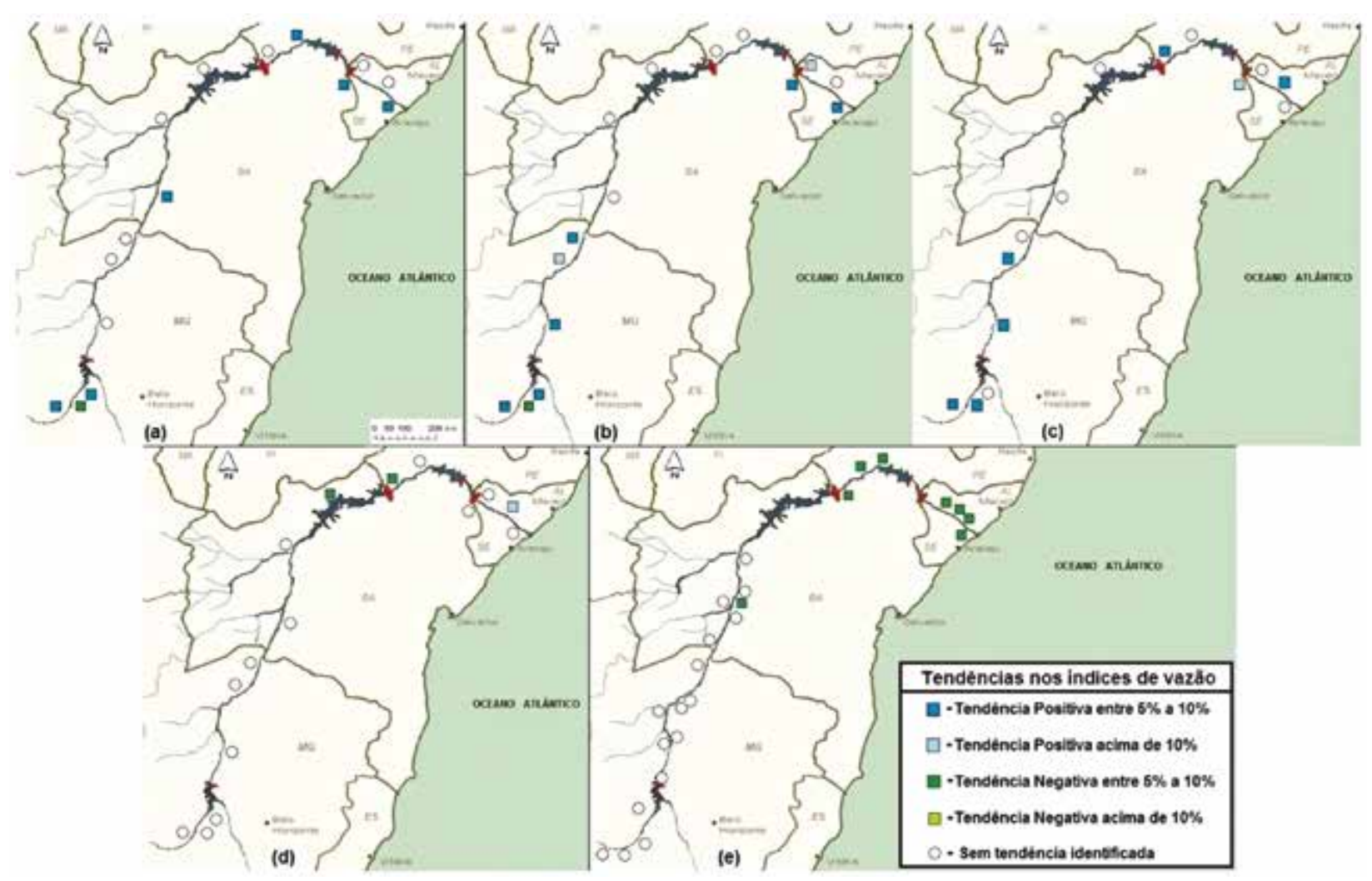

Figura 5 - Distribuição de tendências ao longo do rio São Francisco, como resultado dos testes não paramétricos para: (a) T-mín.; (b) T-méd.; (c) T-máx.; (d) Prec. e (e) Vazão média.

Deve-se reconhecer que o lago formado por Sobradinho cumpre bem seu papel como regularizador do deflúvio do rio São Francisco, porém ele criou um grande problema no que se refere à conservação de recursos hídricos à sua jusante, visto que está inserido numa região de clima semiárido e sob constante influência de ventos alísios provenientes do sudeste. De acordo com Molion (2003), a estimativa de perda de água por evaporação, ao aplicar o método combinado de Penman-Monteith, reconhecido como o mais adequado para estimar a evapotranspiração (SMITH, 1991), atingiu valor médio anual de 460 $\mathrm{m}^{3} \mathrm{~s}^{-1}$ na cota normal de operação do referido lago. Esse valor estimado é próximo do obtido considerando a diferença entre as vazões médias observadas do período 1980 a 1995 da estação medidora de Pão de Açúcar, cujo valor foi igual a $450 \mathrm{~m}^{3} \mathrm{~s}^{-1}$, o que representa uma redução de $15 \%$ da vazão à jusante da Eclusa de Sobradinho (MOLION, 2003).
Ao analisar os mapas climatológicos das Figuras $5 a, 5 b, 5 c$ e $5 d$, observam-se cidades na região da Barragem de Sobradinho com tendências crescentes nas temperaturas T-mín. (Cabrobó, em 1997; Paulo Afonso, em 1983 e Propriá, em 1987), T-méd. (Paulo Afonso, em 1983; Água Branca, em 1981 e Propriá, em 1987) e T-máx. (Petrolina, em 1984; Paulo Afonso, em 1983 e Pão de Açúcar, em 1986), enquanto para o índice de chuvas se identificam locais com tendência decrescente (Remanso, em 1983 e Petrolina, em 1984) e crescente (Pão de Açúcar, em 2003). Por meio desses dados técnicos, julga-se que o clima regional também tenha se alterado com o tempo, culminando em menores índices de precipitação e maiores de temperaturas e evapotranspiração nessas cidades, o que acarretou na diminuição gradativa da vazão do rio desde a Barragem de Sobradinho até a foz, a 748 km do Oceano Atlântico, particular- 
mente devido às mudanças na evaporação pela presença do espelho d'água do lago artificial.

Esse decréscimo na vazão fez-se sentir a partir de 1986, como revelam as quebras de tendências estatísticas das localidades avaliadas e mostradas nas Tabelas 6, e na Figura 5e. Os resultados aqui mostrados indicam que o regime de vazões após a referida barragem até a região próxima à foz do rio São Francisco minimizou os efeitos de cheias. Essa redução das vazões pode também estar associada ao uso consuntivo da água (para fins de irrigação, abastecimento humano urbano, dessedentação animal, além dos abastecimentos industrial e rural) ou então com a forma como a evaporação da Barragem de Sobradinho ocorre no processo de reconstituição de vazões naturais. De qualquer maneira, essa diminuição no regime de vazões vem afetando negativamente as atividades das populações ribeirinhas, como a pesca, a agricultura e a navegação pluvial, em concordância com o que foi identificado por Holanda et al. (2009), por meio de relatos da população ribeirinha do rio São Francisco, em particular no estado do Sergipe.

\section{CONCLUSÕES}

1. Considerando as cinco variáveis hidroclimáticas abordadas, das 84 séries possíveis de serem analisadas, 50 (o que corresponde a 60,0\%) não indicaram quaisquer indícios de tendências significativas.

2. Das 34 tendências confirmadas $(40,0 \%$ de toda amostra tratada), 33 ocorrências foram registradas nas duas últimas décadas do século $X X$, ou seja, em $97,0 \%$ de todos os eventos inferidos.

3. Identificaram-se tendências nas três séries de temperaturas medidas na cidade de Bom Despacho (MG). Nesse caso específico, constataram-se tendências negativas (-)(-) a partir de 1997 para T-mín. e T-méd., além de tendência positiva (+)(+) para a T-máx. na mesma data. O mesmo ocorreu com a cidade de Bambuí (MG), que acusou ten- dência positiva (+)(+) para T-mín. em 1991, T-méd. em 1992 e T-máx. em 1993, e para a cidade de Paulo Afonso (BA) que também registrou tendência positiva (+)(+) para T-mín., T-méd. e (+) T-máx., todas a partir de 1983.

4. Tendências negativas (-)(-) nos índices de chuvas foram registradas em Remanso (BA) e Petrolina (PE) a partir de 1983 e 1984, respectivamente. A cidade de Pão de Açúcar acusou tendência positiva de nível (+), mas somente a partir de 2003.

5. Registrou-se diminuição nos índices de vazão para todas as estações medidoras da ANA localizadas após a Barragem de Sobradinho a partir de 1986. Julga-se que esse fato está associado às condições climáticas daquela região hidrográfica, especialmente devido às ações das temperaturas e da evapotranspiração, além da formação dos reservatórios destinados às usinas hidroelétricas instaladas no rio São Francisco, que compõem o maior complexo energético do Nordeste brasileiro. A construção desse complexo minimizou, devido ao espelho d'água formado, os efeitos de cheias após a barragem, mas vem afetando de forma negativa as atividades tradicionais das populações ribeirinhas que ali vivem.

6. As tendências que foram detectadas nos índices de vazão parecem não estar relacionadas a uma mudança definitiva nos padrões pluviométricos e não devem, necessariamente, estar associadas exclusivamente a uma mudança global do clima. Presume-se que as tendências negativas registradas a partir de 1986 em todas as localidades analisadas após a Barragem de Sobradinho sejam uma combinação de fatores de ordem antropogênica e climática.

7. Os resultados aqui apresentados alertam para o cuidado que se deve ter ao apontar as possíveis causas de mudanças significativas nas séries hidrológicas e climáticas, tendo em vista a complexidade em associar essas alterações com as variações naturais do clima e as influências antro- 
pogênicas. Apesar de todas as incertezas associadas às mudanças do clima e, consequentemente, aos impactos dessas possíveis alterações nas séries hidroclimáticas, como apresentado e discutido anteriormente, estudos nessa linha são relevantes e oportunos para auxiliar gestores de recursos hídricos no cenário atual sobre o comportamento do meio ambiente de uma determinada região.

\section{AGRADECIMENTOS}

Os autores agradecem ao Conselho Nacional de Desenvolvimento Científico e Tecnológico (CNPq) pelo financiamento para o desenvolvimento dessa pesquisa, à Agência Nacional de Águas (ANA) e ao Instituto Nacional de Meteorologia (INMET) pela disponibilização dos dados observados e aqui utilizados.

\section{REFERÊNCIAS}

ALEXANDRE, G.R.; BAPTISTA, M.B.; NAGHETTINI, M. Estudo para identificação de tendências do regime pluvial na região metropolitana de Belo Horizonte a partir de métodos estatísticos. Revista Brasileira de Recursos Hídricos, v. 15, n. 2, p. 115-126, 2010.

ANA. Agência Nacional de Águas. Conjuntura dos Recursos Hídricos no Brasil. 2013. Disponível em: <www.arquivos.ana.gov. br/institucional/spr/conjuntura/webSite_relatorio Conjuntura/ projeto/index.html>. Acessado em: 28/04/2016.

ANA. (2015). Agência Nacional de Águas. Sistema de Informações Hidrológicas, HidroWeb. Disponível em: <www.hidroweb.ana. gov.br>. Acessado em: 17/11/2015.

BACK, A.J. Aplicação de análise estatística para identificação de tendências climáticas. Pesquisa Agropecuária Brasileira, v. 36, n. 5, p. 717-726, 2001.

CODEVASF. (2015). Companhia de Desenvolvimento dos Vales do São Francisco e do Parnaíba. Disponível em: <www.codevasf. gov.br/osvales>. Acessado em: 04/08/2015.

FREUND, J.E. Estatística Aplicada: Economia, Administração e Contabilidade. 11a. edição. Porto Alegre: Editora Bookman,.., 2006, 612 p.

GROPPO, J.D.; MORAES, J.M.; BEDUSCHI, C.E.; MARTINELLI, L.A. Análise de séries temporais de vazão e precipitação em algumas bacias do Estado de São Paulo com diferentes graus de intervenções antrópicas. Geociências, v. 24, n. 2, p. 181-193, 2005.
HAAS, J.; GUETTER, A.K. Diagnóstico e remoção do degrau climático nas séries de vazões naturalizadas mensais do sistema interligado nacional. In: XV Simpósio Brasileiro de Recursos Hídricos - 2003. Curitiba, p. 15-17, 2003.

HOLANDA, F.S.R.; ISMERIM, S.S.; ROCHA, I.P.; JESUS, A.S.; ARAÚJO FILHO, R.N.; MÉLLO JÚNIOR, A.V. Environmental perception of the São Francisco riverine population in regards to flood impact. Journal of Human Ecology, v. 28, p. 37-46, 2009.

IBGE (2016). Instituto Brasileiro de Geografia e Estatística. Censo Demográfico de 2010. Disponível em: <www.cidades.ibge.gov.br/ xtras/home.php>. Acessado em: 02/05/2016.

INMET. (2016). Instituto Nacional de Meteorologia. Banco de Dados para Pesquisa e Ensino (BDMEP). Disponível em: <http://inmet.gov.br> Acessado em: 18/02/2016.

IPCC. (2016). Intergovernmental Panel on Climate Change 2014: Summary for Policymakers. In: Climate Change 2014: Impacts, Adaptation, and Vulnerability. Field, C.B., et al. (eds.). Cambridge University Press, Cambridge, United Kingdom and New York, NY, USA, p. 1-32, 2014. Disponível em: <www.ipcc-wg2.gov/ AR5/images/uploads/WG2AR5_SPM_FINAL.pdf>. Acessado em: 15/06/2016.

MARENGO, J.A. Mudanças climáticas globais e seus efeitos sobre a biodiversidade: caracterização do clima atual e definição das alterações climáticas para o território brasileiro ao longo do século XXI. Ministério do Meio Ambiente, Secretaria de Biodiversidade e Florestas. 2a. edição. Brasília: MMA, v. 26, 212 p., 2007

MMA. Ministério do Meio Ambiente. Caderno da Região Hidrográfica do São Francisco. Secretaria de Recursos Hídricos. Brasília: MMA, 148 p., 2006.

MARTINS, D.M.F.; CHAGAS, R.M.; MELO NETO, J.O.; MÉLLO JÚNIOR, A.V. Impactos da construção da usina hidroelétrica de Sobradinho no regime de vazões no Baixo São Francisco. Revista Brasileira de Engenharia Agrícola e Ambiental, v. 15, n. 9, p. 1054-1061., 2011.

MEEHL, G.A.; STOCKER, T.F.; COLLINS, W.D.; FRIEDLINGSTEIN, P.; GAYE, A.T.; GREGORY, M.; KITOH, A.; KNUTTI, R.; MURPHY, J.M.; NODA, A.; RAPER, S.C.B.; WATTERSON, I.G.; WEAVER, A.J.; ZHAO, Z.C. Global climate projections. In: Solomon, S.; Qin, D.; Manning, M.; Chen, Z.; Marquis, M.; Averyt, K.B.; Tignor, M.; Miller, H.L. (eds.). Climate change 2007: the physical science basis: contribution of Working Group I to the Fourth Assessment Report of the Intergovernmental Panel on Climate Change. Cambridge University Press, Cambridge. p. 749-844., 2007.

MOLION, L.C.B. Considerações sobre a interligação da bacia do Tocantins com a bacia do São Francisco. Revista Ciência Hoje, ed. 197, setembro, 2003.

MORAES, J.M.; PELLEGRINO, G.; BALLESTER, M.V.; MARTINELLI, L.A.; VICTORIA, R.L. Estudo preliminar da evolução temporal dos 
componentes do ciclo hidrológico da bacia do Rio Piracicaba. In: XI Simpósio Brasileiro de Recursos Hídricos; II Simpósio de hidráulica e recursos hídricos dos países de língua oficial portuguesa. 1995. Anais. Recife: Associação Brasileira de Recursos Hídricos. p. 27-32., 1995.

PETTITT, A.N. A non-parametric approach to the change-point problem. Applied Statistics, v. 28, n. 2, p. 126-135., 1979.

SANSIGOLO, C.A.; NERY, J.T. Distribuição de extremos de temperatura mínima no estado do Paraná. Revista Brasileira de Agrometeorologia, v. 8, n. 2, p. 247-253., 2000.

SELLO, S. Time series forecasting: a nonlinear dynamics approach, 1999. Disponível em: <www.arxiv.org/abs/physics/9906035>. Acesso em: 14 abr. 2015.
SMITH, M. Report on the expert consultation on revision of FAO methodologies for crop water requirements. Rome FAO. 45 p., 1991.

SNEYERS, R. Sur l'analyse statistique des séries d'observations. Genève: Organisation Météorologique Mondial, Note Technique. n. 143, 192 p., 1975.

TOLEDO, K. Quinto relatório do IPCC mostra intensificação das mudanças climáticas. Revista da Agência FAPESP., 2013. Disponível em: <http://agencia.fapesp.br/17944>. Acessado em: $30 / 09 / 2013$.

ZHENMEI, M.; SHAOZHONG, K.; LU, Z.; LING, T.; XIAOLING, S. Analysis of impacts of climate variability and human activity on streamflow for a river basin in arid region of northwest China. Journal of Hydrology, v. 352, n. 3-4, p. 239-249., 2008. 